\title{
Research on the BEIC Curriculum: Unveiling What Lies Under the Tip of the Iceberg ${ }^{1}$
}

\author{
l , Istavo Álvarez Martínez ${ }^{2}$ \\ Ilı ıversidad Nacional, Costa Rica \\ Ninndayure Valenzuela Arce $^{3}$ \\ Ilı ıversidad Nacional, Costa Rica
}

\section{Resumen}

Es un detenido análisis de la investigación The Value of Curricular Introspection, en que se incorpora la realimentación dada por diversos participantes nacionales y extranjeros en el CILAP 2007, a quienes se les expuso los resultados iniciales de esta investigación. El estudio surgió de la disparidad de criterios entre diversos actores del BEIC, de la ELCL, respecto a la pertinencia que para la enseñanza del inglés a niños en Costa Rica tienen los principios comunicativos denominados interacción, inmersión parcial y aprendizaje por experiencia. Así. mientras diseñadores de currículo y profesores del BEIC consideraban estos principios altamente eficaces, buena parte del estudiantado que realizaba la práctica docente pensaba lo contrario.

\section{Abstract}

A detailed analysis is provided here of the research project titled The Value of Curricular Introspection. It also includes the feedback given by the

Article based on paper presented in the I Congreso Internacional de Lingüística Aplicada. CILAP), held in October 2007 (Campus Omar Dengo, Universidad Nacional, Costa Rica). We wish to acknowledge the support of the ELCL: since this research reveals possible weaknesses in the BEIC curriculum, not all institutions would agree on making findings like these open to the public, as they were in CILAP, where both national and international participants enhanced this research with their feedback.

Correo electrónico: lgtavo@yahoo.com

Correo electrónico: nandayure.valenzuela@ice.co.cr 
national and foreign participants in CILAP 2007, to whom this study was presented. The investigation emerged from the diverse opinions existing among BEIC-ELCL actors regarding the pertinence of interaction, partial immersion and experiential learning communicative principles for the teaching of English to children in Costa Rica. Thus, whereas BEIC curriculum designers and professors considered these principles to be highly effective, many student-teachers in that program believe just the opposite.

Palabras clave: interacción, inmersión parcial, aprendizaje por experiencia, currículo, enseñanza del inglés a niños

Keywords: interaction, partial immersion, experiential learning, curriculum, teaching English to children

This research examines the curriculum of the Bachelor's degree in Teaching EFL in Primary Schools (BEIC) ${ }^{4}$, a program that is jointly managed by two schools: the School of Literature and Language Sciences (ELCL) and the Center for Investigation and Teaching in Education (CIDE), ${ }^{5}$ at the National University of Costa Rica (Universidad Nacional, UNA). The BEIC is one of the very few formal programs training professionals in Costa Rica to teach English to children using a comprehensive implementation of communicative methodology. Here we present the results of only the first phase of the research since the second is still in progress.

\section{The Research Problem}

Because of the proven efficiency of communicative principles for teaching second/foreign languages to children, ELCL curriculum designers of the BEIC program have set these principles as the foundation for the curriculum of this major. However, it was observed that there was a divergence in thought between the BEIC student-

4 Bachillerato en la Enseñanza del Inglés para I y II Ciclos. con Salida Lateral de Diplomado (BEIC).

$5 \quad$ Escuela de Literatura y Ciencias del Lenguaje (ELCL): Centro de Investigación y Docencia en Educación (CIDE). 
wachers on the one hand, and the curriculum designers and professors ") 'the program on the other. While the students claimed that interaction, partial immersion, and experiential learning are less important for ( issta Rican children's learning of English, the BEIC professors and iurriculum designers stressed the opposite.

From the BEIC student-teachers' point of view, the applicability II these principles is limited in public primary schools in Costa Rica lncause the educational and cultural conditions impede their implementation. They argued that in most of these schools the groups ire too large (30-40 children per class), therefore making it difficult to ' up group work for pupils' to interact in English. Cultural patterns licre cause children to be reluctant to work in groups. In addition, time ionstraints (only five 45-minute lessons per week) and the uverwhelming English curriculum established by the Ministry of I'ublic Education (MEP, acronym in Spanish) to be covered pose I IIIItations on teachers for the implementation of partial immersion as il way to provide sufficient exposure to the target language (TL). I inally, the student-teachers added that equipment to teach the foreign linnguage (FL) is scarce or not available at all in public schools, so icplicating the outside world for pupils to learn by doing —experiential l'arning-is somewhat utopic.

In contrast to the above, from the perspective of BEIC curriculum W:signers and professors, communicative principles are very pertinent lor teaching English in Costa Rican primary schools, since scholars $11 \mathrm{ch}$ as Brumfit and Johnson, ${ }^{6}$ Allwright and Bailey, ${ }^{7}$ and others, have ' mphasized the relevance that interaction, partial immersion and (xperiential learning have on second language (L2) learning for they consider the complexity and heterogeneity of human beings; (ongruently, in the BEIC curriculum, it is stated that these principles

C. J. Brumfit and K. Johnson. The Communicative Approach to Language (Oxford: Oxford University Press, 1981).

Dick Allwrite and Kathleen Bailey. Focus on the Language Classroom, $4^{\text {th }}$ ed. (Cambridge: Cambridge University Press, 1994). 
provide multiple avenues for individuals to address knowledge meaningfully, shaping and making input learnable. ${ }^{8}$

Likewise, communicative principles have been tested by the ELCL and proven pertinent to children's learning needs. In Costa Rica, the ELCL has been a pioneer in the implementation of communicative approaches, the design of didactic materials and applied research. In addition, the ELCL has provided training based on communicative principles for students in the other Bachelor's degree program (Bachillerato en la Enseñanza del Inglés, BEI)—directed to training teachers to instruct adolescent and adult FL learners. This training has also been provided for primary-school in-service English teachers participating in the ELCL outreach program for EFL elementary school teachers (Programa de Capacitación para Profesores de Inglés de I y II Ciclos, PROCAPRI). As a result, most of these trainees have been able to use communicative principles effectively by developing diverse teaching strategies to comply with the educational and cultural conditions of Costa Rica; unfortunately, the situation is somehow different for the BEIC students.

The fact that an important number of BEIC student-teachers questioned the efficiency of these L2 communicative principles to teach English to Costa Rican children triggered current study. However, this was only a symptom of deeper curricular weaknesses that emerged gradually as the research has progressed. These inconsistencies have affected these students' training process. Soon, external curricular factors were disregarded since data analysis pointed to several components and participants of the BEIC curriculum as the sources of educational weaknesses; accordingly, an introspection of the major's curriculum was deemed necessary.

Guiselle Miranda. Rafael Jiménez and Lelia Villalobos. Plan de Estudios de la Carrera de Bachillerato en la Enseñanza del Inglés, con Salida Lateral de Diplomado (Heredia. UNA. 2004) 18-19. 


\section{I'he Pertinence of the Study}

This research is pertinent for the BEIC program, its studentl'achers, and primary school children because communicative principles deal directly with the FL teaching and learning objectives 1) this major and the English curriculum of the MEP. ${ }^{9}$ It is hoped that lice resulting recommendations will help eliminate the weaknesses lound in different elements of the BEIC curriculum, and will increase llic students' confidence in the usefulness of communicative principles. I'his, in turn, can help them deal appropriately with teaching/learning variables that (in class) pose negative effects on the practicability of lliese principles. Consequently, students will be more likely to motivate primary school pupils, prompt them to accept challenges, and increase lheir desire to interact in English.

\section{Methodology}

This research was oriented by a multimodal (qualitative/ (fuantitative) approach due to the need to examine diverse scenarios ind populations from different angles. The attempt was to implement mainly exploratory studies, complemented by elements of explanatory ind statistical studies. The data was collected through 1) a literature review of primary sources: a search for previous studies on interaction, partial immersion and experiential learning communicative principles; 2) two types of observations in two different settings: overt nonparticipant observation of four BEIC student-teachers and their primary school students (first and second grade) in the English class, and covert participant and non-participant observations of the BEIC students in the UNA course "Didactics of Oral and Written Communication (LLE-408T); 3) a survey: inasmuch as it was required to determine whether the present investigation problem was a particular or a general

Ministerio de Educación Pública, Programas de estudio 2005: Inglés (I Ciclo) e Inglés (II Ciclo) (San José. Costa Rica: Imprenta Nacional, 2005). 
one, the sample population was enhanced, so the perspectives of all four levels of BEIC students were examined; 4) an open unstructured interview (the views of eight professors from the major were examined using this data collection instrument); and 5) a parallel investigation focusing on the pertinence of six communicative principles (including those emphasized here) carried out by BEIC students of the course LLE-408T, who at the same time, were subjects of our investigation.

\section{Theoretical Considerations}

Efficient communicative approaches such as Communicative Language Teaching (CLT), Content-Based Instruction (CBI), and Theme-Based Instruction (TBI) havebeen developed inrecent decades. Their holistic/comprehensive view of language and emphasis on having students use it appropriately for real-world purposes have generated teaching principles that trigger students' cognitive, emotional, and psychomotor domains. Savigon emphasizes that "for students' L2 interaction success, communicative classrooms should promote learning experiences that involve the whole learner." ${ }^{10}$ The learners can approach the TL through diverse means of perception that enable them to connect input meaningfully and achieve stable long-term learning sooner.

Some of the most representative communicative principles that teachers can select from the above approaches are: 1) encouraging the implementation of both dimensions of FL interaction, to work out input for its comprehension and to approach individuals for communication exchanges; 2 ) providing partial immersion in the TL to allow students more exposure to its input; and 3) designing experiential communicative language learning activities that provide concrete experiences through which learners are led to discover

10. Amulfo Ramírez. Creating Context for Second Language Acquisition: Theor and Methods (London:
Longman, 1995) 8. 
principles of the L2, thereby building their own knowledge by using l. $/$ t and right brain processing activities. ${ }^{11}$

Nevertheless, to facilitate students' FL proficiency using 'ommunicative principles, instructors need to identify and analyze the is pects that - given conditions of the educational setting and students' ind teachers' as well-facilitate or constrain the teaching/learning processes. To deal with the weaknesses of these processes, Kathleen ( iraves advises teachers to "problematize"; i.e., "...teachers need to ilentify the [teaching/learning] challenge(s), analyze all options, determine which individuals could help, and make a plan (strategies) 11) carry it out" (in Richards). ${ }^{12}$ It is equally important to recognize the positive conditions available to strengthen $\mathrm{L} 2$ teaching and learning, hecause instructors who are aware of these givens can use them more ' "'lectively to develop the students' language proficiency. L2 teachers should understand the theory of language and learning underlying interaction, partial immersion, and experiential learning of communicative principles, and analyze the conditions that make them work appropriately and those that do not.

\section{Analysis of Data Collected Through Observation and a Parallel Study}

This analysis is based on the results of the observations carried out in our own research on communicative principles, and is compared (1) the results obtained by the BEIC student-teachers' in their parallel study. The perspectives of experts on communicative principles serve in a theoretical framework and orient this discussion. A narrative style is used here to portray in a more meaningful way the views and feelings of the subjects under study: BEIC professors, student-teachers, primary school learners and the researchers themselves.

Rod Ellis. The Study of Second Language Acquisition, $7^{\text {th }}$ ed. (Oxford: Oxford University Press, 2000): see Ch. 9.

Jack Richards (ed).. Teachers as Course Developer: $4^{\text {th }}$ ed. (Cambridge: Cambridge University Press. 1999) 33-35. 


\section{Interacting with Input and Output}

There are two dimensions of interaction: one in which children manipulate the TLinput, and the other in which the pupils use English to engage actively in communicative exchanges. For children to interact with L2, incoming stimuli must be scaffolded to help them develop strategies to know how to go about making data comprehensible.

Although the BEIC student-teachers used communicative lesson-plans including some of the above conditions (comprehensible input and learning strategies), it became evident during these lessons that some pedagogical materials and teaching procedures did not provide enough support for the comprehension process. For example, two of the novice teachers used picture-cards intended to help their pupils to relate the illustrations and a story (in one case) and a dialogue (in another). Prior to showing the pictures, the novice teachers prepared the children for comprehension by having them brainstorm about the topic (strategy: using learners' background knowledge), writing the title and other main information of the story on the whiteboard to allow students to read (strategy: using other language skills to let input be perceived through a different cognitive channel), and asking learners simple questions that served as clues to lead the children to infer what the content of the input would be about (strategy: inferring).

These teaching activities are also learning strategies taught implicitly; this helped students participate actively and watch for what was coming up next. Up to this point, students' motivation was high for they were understanding and producing a little in English. Nonetheless, when the teachers showed the picture-cards that illustrated the input, the elements on the illustrations were too small to be visible for students seated three or more rows away from the instructor. In addition, the picture-cards were not colorful or appropriately framed. This caused some learners in the middle and back rows of the class to become anxious because they could not see 
what was in the pictures. Some of the pupils tried to get closer by hending forward until they got bored and began to look away or do something else instead of paying attention.

This situation emphasizes the importance of designing attractive pedagogical materials (such as picture-stories, letters, post-cards, poems, videos) to encourage students to interact effectively with L2 input. This type of material and the respective communicative tasks 'ngage students actively in processing information meaningfully from different perspectives. In addition, skillful communicative instructors show students how to go about their interaction with input (1) build knowledge creatively. "The features to be internalized are discovered by the learners themselves, from the language environment arround them," as Littlewood has stated,${ }^{13}$ and this process is carried wut through learning strategies such as brainstorming, inferring, raasoning and cooperating with others, which are taught to learners Implicitly and explicitly.

It was difficult for us to understand why BEIC student-teachers liad not reported in their parallel research what we had detected through (1) $)$ servation as a very obvious teaching mishap: the observees' use of Inlattractive and low-quality pedagogical materials and the effect they liad on some of the primary school students. This detail could not hilve escaped the monitoring of the student-teachers since they all liad taken a previous course on materials design in which the quality was emphasized and appropriate models were presented. In fact, the wdents themselves had designed some high-quality materials lollowing specific guidelines for creating attractive products that could Iruly raise children's interest and improve their comprehension of the III. input. It may be that the BEIC student-teachers, although they were aware of the inappropriateness of the materials presented in the primary school class, did not point this out probably due to affective considerations towards the classmates being observed, or because they

\footnotetext{
1 William Littlewood. Foreign and Second Language Learning. $12^{\text {th }}$ ed. (Cambridge: Cambridge University Press. 1996) 78.
} 
did not know how to write an objective observation report. Nevertheless, our own observation reports provide sufficient evidence that the use of inappropriate pedagogical materials was an element that interfered with good interaction with English input, which the children had been accomplishing during pre-listening activities.

Another breakdown in comprehension occurred when one of the BEIC students told a story without showing picture-cards to illustrate the events while she was reading. The instructor had asked them to use picture-cards before telling the story and had encouraged the pupils to describe the elements in the pictures relying on their previous linguistic knowledge. She provided the new vocabulary and asked the children leading questions to help them practice the new lexicon and structures meaningfully. The students who could see the pictures were engaged in the interaction with input activity, but when the instructor put the pictures aside and read the story with no reference to the illustrations, the pupils got frustrated because they could not relate what they were listening to with the images provided.

The problem is that learners' interaction with the FL and the materials facilitating comprehension should be handled by using different procedures to give children time, sufficient exposure, and practice to enable their internal mechanisms to make the input learnable. For this reason, the picture-cards were shown as the story progressed, since this was a key moment in the interaction process in which learners could gather final clues to establish relationships between the story input and the illustrations in order to attain at least a general comprehension of the content of the story.

The pre-listening activities were implemented correctly and helped students interact with the TL input, but the while-listening stage was dealt with inappropriately. The students had no opportunity to interact with the story while the BEIC student-teacher was telling it nor were they stimulated to use any other comprehension strategy since they were left with no visual clues, thus reacting passively.

The same occurred when a BEIC student-teacher who presented a dialogue made another wrong decision: to support students' 118 
(omprehension, the novice-instructor used picture-cards for a dialogue in which people made introductions, but not all materials work well in all learning situations. Here, it would have been better to use puppets, dolls, stuffed animals, or other materials that could make movements. People from different cultures employ diverse forms of hody language for introductions, and materials of this sort can be used to imitate the hand-shake, kissing on the cheek, and other Costa Rican gestures, to enable children to realize that the dialogue is about a two-(or more) way interaction in which people introduce themselves.

In addition, this student-teacher asked questions in the prelistening stage that were not appropriate for students interacting in linglish. Her students were first graders and she asked them: "What is an introduction?" and "What is a song?" The students would not know the answer even if asked in Spanish, and as an open question, the children were not able to answer it in English for it demanded oral production using language that they had not yet learned. Therefore, the students remained silent. Asking questions to have pupils interact with the TL input is a very effective teaching strategy that can stimulate them to work with input, yet the right questions have to be asked according to the students' academic, linguistic, social, and affective competence.

For children in the lower grades, it is always more effective to guide their interaction through yes/no questions; the answers to these questions require students to use very simple and short wording that heginners can manage. As the session progresses, teachers can ask the opposite to confront students with something obviously not true and allow them to correct the teacher (which they love to do). For example, instructors can show a stuffed-pig and ask, «Is this a rabbit?» Then, children can answer, "No, it's a pig.» The type of questions grew in complexity as the learners attained a better command of the new input and gave more complex answers.

Notwithstanding the above, other BEIC students used appropriate materials, introduced learning strategies to interact with 
input, and implemented the right teaching procedures, along with nonverbal communication skills to make input learnable. Samovar, Porter and Stefani state that "many...of the critical meanings generated in human encounters are elicited by touch, glance, vocal nuance, gestures, or facial expression with or without the aid of words." ${ }^{14}$ We observed a student-teacher telling a story in which the main visual and aural source was herself. She was so skillful with body language that the children did not require much English. The student-teacher was telling the story through her body movements and facial expressions; in addition, she used effective paralanguage to imitate the character's voice and give them personality. The students followed the teacher's physical and oral expressions attentively, and their comprehension of the story was confirmed when they were asked to draw a picture of the story. We examined the children' drawings and they all portrayed the characters and events in the story.

The other dimension of interaction deals with students' engaging in communicating with others. Due to the limited socio-cultural target context in a FL educational setting, the replica of social interaction through English is even more determining for TL students. The best way for pupils to use the language meaningfully is in pairs, triads and small groups. This technique allows each pupil more opportunities to use English and implement different communication strategies to send messages and decode the ones that they receive. Brown states that "Group work is in itself a stimulus to communicate; it also provides students more opportunities and time to speak, enables individuals to produce more socially-appropriate output by assuming roles, lowers pupils affective filter since they are performing for a smaller community (their group-mates), and endows students with autonomy and responsibility for their own skills development." 15

\footnotetext{
14 Larry Samovar. Richard Porter and L.isa Stefani, Communication Between Cultures (Rowley. MA: Wadsworth. 1998) 147-148.

is Douglas Brow'n. Principles of Language Learning and Teaching. $3^{\text {rd }}$ ed. (Englewood Cliffs. N.J.: Prentice Hall. 1994) 175.
} 
We observed that the BEIC student-teachers did use this principle, but not always appropriately. In all their English classes, there was at least one activity to be carried out in pairs and small groups. Before formulating this research, we had heard some teachers question the pertinence of group work English classes in Costa Rica: Two of the arguments were that 1) the technique is impractical in large classes because it can cause disorder and take up class time, and 2) pupils reject working with others due to their individualistic cultural patterns. Samovar, Porter and Stefani point out that "due to cultural perceptual differences, people in a given culture may be field-sensitive (prefer to work with others) and in another, field-independent (prefer to work independently), and this is reflected in the classroom." 16 However, we confirmed that these children's cultural patterns were not an obstacle to group work. Most of them seemed to enjoy spending time with a classmate and using English without the threat of being exposed to the scrutiny of the whole class. In addition, Brown explains that some instructors avoid this type of interaction because they feel that they [teachers] lose control and cannot monitor all the groups to provide feedback; he goes on to state that for these instructors, groups can provide a setting for students to use their native language (instead of English), reinforce their errors and that-anyway—some learners prefer to work alone. ${ }^{17}$

Nevertheless, it was observed that, whenever the principle failed, it was because the BEIC students did not know what they had to do. It was painful for us to see children who were confused; we could see how uncomfortable they felt. Leading students to use the TL is not just telling them to pair up and talk, there must be sufficient practice, a meaningful purpose for carrying out the task and clear instructions to orient the performance. In other words, "teachers must structure the situation so that learners have to overcome an information gap or

6 Samovar. 206.

17 Brown. 1994. 175-178. 
solve a problem...they are the stimulus for communication and the yardstick for success," Littlewood ${ }^{18}$ ascertains.

In one class, the students had to re-tell a story and they were grouped to help each other practice the story before retelling it in front of the whole class. In this particular case, they had not interacted enough with the story to learn basic vocabulary from it. When the teacher gave instructions on what they had to do in the groups, she did not present this information appropriately. The use of non-verbal communication (especially body language) is a skill this teacherstudent did not use much in the class, so some of her students were left behind in comprehension. In addition, because the students had had little verbal practice on the lexicon and structures to retell the story, the pupils' resource was to write the sentences under the picturestory and use them to guide their performance in front of the class. At the end, they could only read, and not retell the story.

In their data analysis, the BEIC student-teachers ${ }^{19}$ acknowledged that diverse types of group arrangements can facilitate children's possibilities for linguistic and social interaction, although in real life, some of them fail to apply the technique. The novice teachers pointed out that sometimes letting the students choose who they want to work with is a way to enable them to feel comfortable working with their peers, but the students also stated that it is important to alternate this practice with instructors' randomized selection of individuals to make the small groups and promote the integration of shy students with the rest of the class.

According to one of this BEIC student-teacher's observation report, in a class where the children had to retell a story in front of the group, the novice-teacher chose pair work, but this student-teacher was not too skillful with non-verbal communication, and provided instructions but without supporting them with extra-linguistic

\footnotetext{
is Littlewood. 223.

19 Karen Carballo. Adriana Chaverri et al.. "Research on Communicative Principles to Teach English to Children“" (Heredia. Costa Rica. 2006).
} 
information. She consequently failed at having the children understand what they had to do in the pair work, so they were confused and some misbehaved. From one of the BEIC student-teachers' point of view as an observer of this class, the problem was the lack of authority that the novice-teacher displayed, because some children were noisy, misbehaved, and/or did not work at all. This observer also reported that the pupils did not react positively when asked by the noviceinstructor to be quiet, go back to their seats, and work on the task. Although we agree with the observer on the fact that the BEIC noviceteacher did not have much authority in class, we have also hypothesized that the children's interest had dropped at the moment that they were left on their own without suitable instructions for them to know exactly what they were expected to do and how to go about the task in pairs.

In other cases (the majority) in which group work instructions were clear, the children focused on the pair or group work knowing what to do and how, and later they seemed to be proud of being able to perform orally in the communicative task that they had been assigned to do. Consequently, using non-verbal communication skills to complement instructions for small group work is essential for students to take advantage of the possibilities that diverse group arrangements provide.

\section{Learning English through English}

We did not expect to discover that some of the BEIC studentteachers believe that partial immersion (teaching English through English) is not valuable for FL teaching. Curtin and Pesola emphasize that "Using the TL as the exclusive means of communication in the class provides meaningful clues to accelerate the comprehension of diverse data that will become the basis for students' oral production. ${ }^{20}$

5) Helena Curtain and Carol Pesola. Languages and Children: Making the Match (New York: Longman. 1994) 107. 
It was even more surprising to verify in the analysis of the observation reports that frequently, in spite of being aware of our presence, a novice-teacher could not avoid using more Spanish than English to implement her communicative lesson-plans.

In the BEIC major, the students have been made aware of many arguments that illustrate the relevance that partial immersion has for children's FL acquisition success, but still some of them continue to defend-with varying degrees of conviction-the argument that Spanish should be used as a tool in the English class. In particular, one of these novice-teachers ${ }^{21}$ said that initially Spanish is necessary to enable students to understand English input, and English can be introduced later. This statement shows that learning English through English has been the most controversial issue discussed by the BEIC student-teachers in their parallel research analysis sessions.

As advocates and practitioners of the partial immersion principle - and also as believers that students should address different teaching approaches through a critical perspective-we encouraged the students to feel free to discuss the strengths and weaknesses of any teaching principle; however, in our role as guides of the BEIC novice-teachers' parallel research project, we also advised them to support their positions in regard to the issue with strong arguments derived from their own teaching experiences and field and bibliographic research. One BEIC student-teacher in favor of using Spanish in the English class failed to prove that her argument is correct, yet she continued to be skeptical about the real chances for the practicability of the partial immersion principle in primary schools in Cost Rica, especially the public ones. Another BEIC student-teacher had somewhat modified her beliefs about the utility of Spanish to teach English. since in the student-teachers' discussion sessions at the UNA class, she became aware that using the children's native language is not going to help them learn English.

$\overline{21 \quad \text { Carballo et al. }}$ 
Aside from these novice-teachers' beliefs about teaching English through English, three interesting issues emerged from observing them teaching the TL to children in the primary schools where they work: 1) Once the students had used Spanish in the English class repetitively, they had the tendency to increase its use as the class was developed; 2) there was a correlation between student-teachers' use of English or Spanish and the language the children used to approach the learning process; and 3) student-teachers were not aware of the real amount of Spanish they used in class.

In the first case, the BEIC student-teachers tended to increase their use of Spanish in the English class. Some switched from the FL to Spanish when they felt that their English oral output was not understood by the children in the first or second attempt, so complete translation of input was provided. Often, two of the novice teachers gave instructions in Spanish to have the students carry out a task without having tried to orient them in English first. Scolding the students for a given reason was also done in Spanish most of the time. Hence, the use of Spanish increased as the class developed, until it turned out that Spanish was being used more than English.

The following frequency-polygon graphs portray the behavior of two of our observees in regard to their implementation of the partial immersion communicative principle (using English to teach English). The $x$-axis represents eighty minutes of observation of two classes, forty-minutes each; we divided this time-line in four twenty-minute intervals to illustrate the student-teachers' behavior in each period. The y-axis represents the instructors' amount of oral entries (BEIC student-teachers and children's oral output) in English and Spanish as recorded in our observation reports; the intervals have a distance of 1 point. In the first graph, the BEIC novice-teacher is distinguished as (NT1) and in the second. another novice-teacher is characterized as (NT2). 


\section{Graph 1}

\section{Rising Tendency of the Use of Spanish}

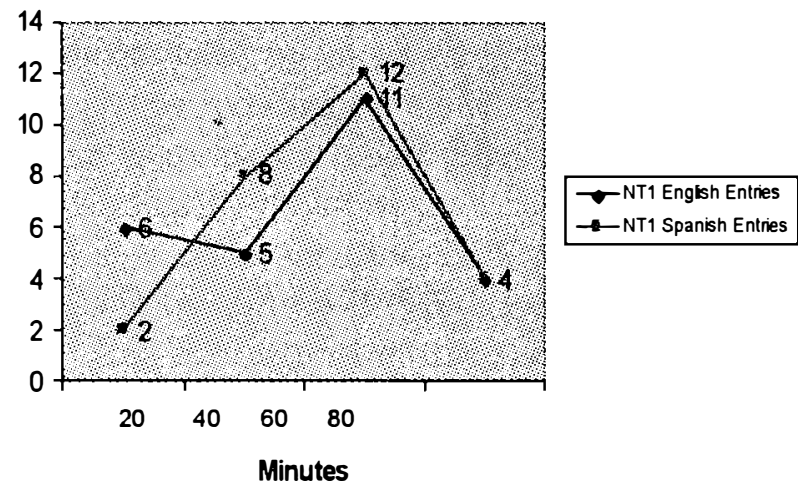

\section{Graph 2}

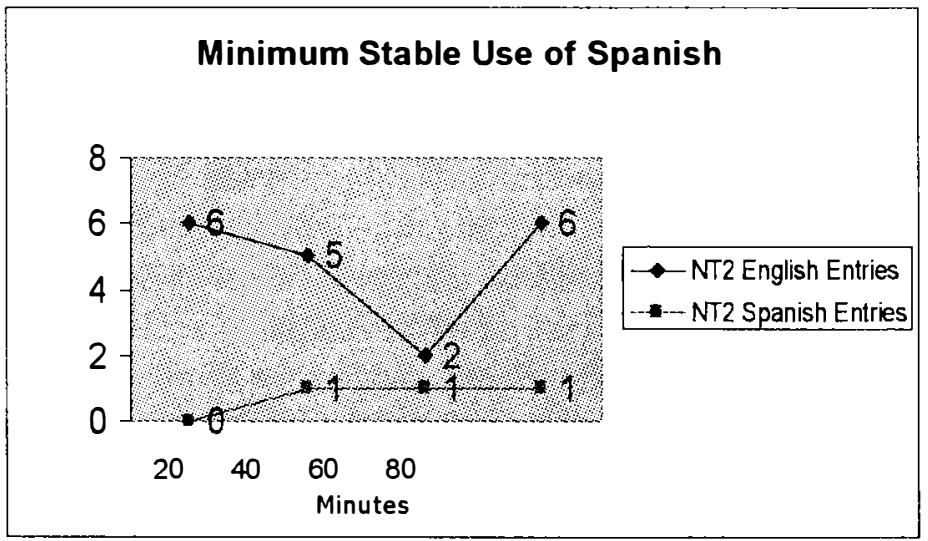

Comparing both graphs, we can observe that when teachers use Spanish in class with some frequency, they tend to keep using it and 126 
make only weak attempts to turn back to English. In graph 1, we can see that in the first 20 minutes of the class, NT1 used much more English than Spanish. As the class was developed, the instructor increased her use of Spanish, until she was providing more Spanish than English input to her students. On the other hand, we can see in graph 2 that NT2 began the class teaching in English and continued using it for almost all purposes for the rest of the session; she only used Spanish on three occasions during the eighty-minute session. As pointed out above, NT1 used Spanish to enable children to understand the English contents that she was teaching, give instructions, and scold students who were misbehaving. NT2 used Spanish for almost the same purposes, but only on three occasions: once to give brief instructions and twice to scold students. Using Spanish for the specific purposes stated above was also observed in a third BEIC novice-teacher, and the fourth did not use Spanish at all during FL instruction with children.

Therefore, we can hypothesize that giving instructions and scolding students are the two strongest conditions that tempt instructors to use the learners' native language. Some observation reports indicate that most of the BEIC students believe that it is difficult to scaffold instructions because it takes time to make abstract word clear. In the instructors' perspective, making complex words/sentences comprehensible cannot of ten be achieved efficiently by using concrete teaching strategies such as visuals and body language; instead, they must use explanations, examples, synonyms, and others (strategies to which teachers must devote great effort and precious minutes if they are to be implemented correctly).

With regard to the investment of time to scaffold English comprehension, a BEIC novice-instructor ${ }^{22}$ claimed that «... it is much more productive if time is assigned to the children's development of the exercises or communicative tasks.» In our experience, however,

$\overline{22 \quad \text { Carballo et al. }}$ 


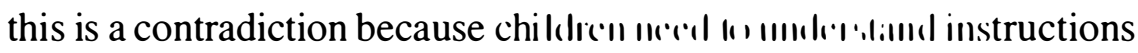
first if they are to perform well on a f!Iv('Il l'illull1! linsh, so the time

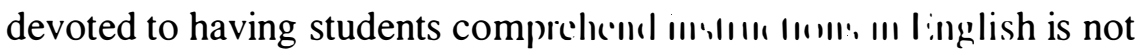
a waste but actually a necessary condition lı lin Ilıillc llocir learning process and keep them motivated. Iı I:I 1 . Allwıl!!ll and Bailey

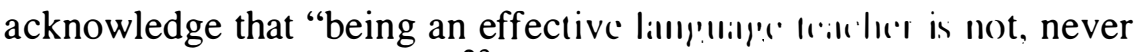

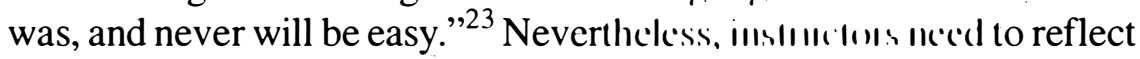

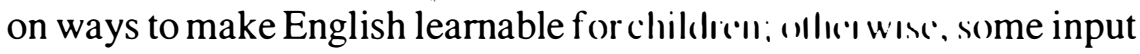
will never become intake.

We have recorded children's chang( o) allilull lir)m attentive to confused, embarrassed, or even angry whe'll llicy (lo ll() know what they have to do, and their frustration is shown hy mishchaving or remaining aloof. In addition, although it is lluc llall giving the instructions in Spanish allows students to know whill llicy have to do, this practice also has two consequences: 1) (he ( () mmmumicative task is made a decontextualized one for instructions inclucle lexicon that will be required by the pupils to carry out llic lissk in Iinglish, so when this input is provided in Spanish, the children arc locing deprived of some data to perform appropriately; and 2) educialurs are sending children the message that English is not relevant in the class (anyway there is Spanish to communicate, children would conclude), so the FL will be seen as purposeless.

Notwithstanding this position of some BEIC student-teachers, we have observed that when they support English input with nonverbal communication clues, visual aids, and different teaching strategies (explaining, giving examples, etc.), children do attain comprehension. "These techniques," according to Curtain and Pesola, "link language very clearly to their meaning for they appeal to the right hemisphere of the brain...adding to the impact of the information." 24 We agree with the student-teachers in that having pupils understand the TL data in English and takes more time and

Allwright, 196 .

24 Curtain, 90.

128 
effort, yet once the children have developed learning strategies to make input meaningful and are used to exerting effort in doing the required cognitive work, the use of these strategies will become automatic to them and therefore less demanding. When we train students to accomplish a task, they enjoy the challenge of learning how to solve the comprehension puzzles by themselves.

A second condition that we noted in the observation reports has to do with a correlation between BEIC student-teachers' use of English or Spanish and the language the primary school learners used to approach the learning process, their teacher, and their classmates. Very often, the more a teacher used the L2, the more her students used English to approach the TL input and carry out different types of interaction; on the other hand, the more a teacher used Spanish, the more her students used their native language to address input provided by the teacher and for interaction. The correlation between instructors' and children's outcomes is portrayed in the graphs. In graph 3, the reader can note the effect that two BEIC student-teachers' use of Spanish had on their students' verbal responses, and in graph 4, the effect that instructors' use of English had on pupils' speech. In each graph, the y-axis shows the percentage of language entries (in Spanish or English) that the BEIC novice-teachers and their students made.

\section{Graph 3}

\section{Spanish Correlation}

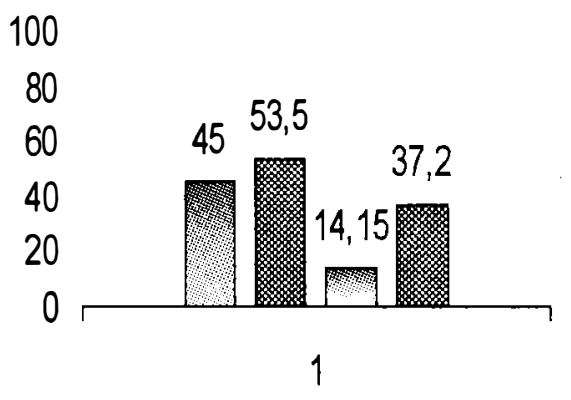

NT1

圈 VT1 Students

NT2

VT2 Students 


\section{Graph 4}

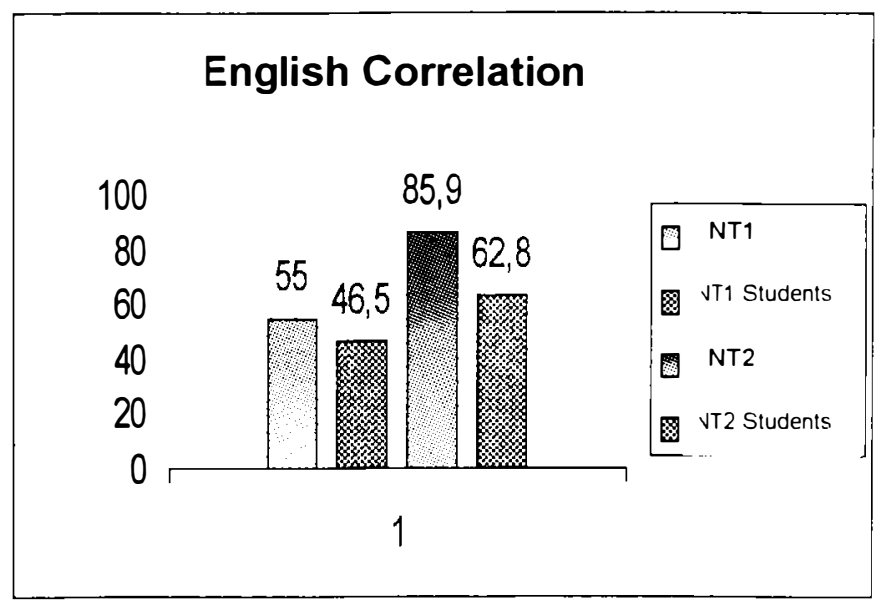

These graphs show that the more Spanish a teacher spoke in class, the more Spanish was used by her students; likewise, the more English a teacher spoke, the more English the learners used. In graph 3 , NT1 spoke Spanish $45 \%$ of the time, and her students used their native language $53.5 \%$ of the time. In contrast, we see in the same graph that NT2 used $14.15 \%$ of Spanish and her students $37.2 \%$. Graph 4 also portrays the language correlation, and it can be observed that NT1 used English around 55\% of the time and her students oral production in the FL was 46.5\%. NT2 used more English (85.9\%), and her students $62.8 \%$. The decrease in Spanish and increase in English from NT2's students is evident. This is even more meaningful when taking into account two situations: a) the students are beginners who, therefore, have very low TL competence, so very little production in English can be expected from them; and b) as researchers, we registered all the utterances produced by the students. Even the children's conversations among themselves and those not related with the FL topic studied were included to conform their total response to the teacher's use of a given language. 
Consequently, the correlation given is an indicator that partial immersion helps students achieve more progress in English. However, we have to consider the effect of two independent variables as causes for the students' higher or lower use of the FL. The first is related to the proficient use of non-verbal communication skills that NT2 has developed and used in class to make herself be understood. Kinesics, posture, facial expressions, eye contact, silence, paralanguage (vocal characterizers: laughing, crying, whining, yawning; vocal volume: pitch, rhythm, tempo; and vocal segregates, among others) are essential; Genelle Morain affirms that "...sixty five percent of the social meaning of a typical two-person exchange is carried by nonverbal cues...."25 During the implementation of NT2 communicative lessons, this instructor used body language to show what she was indicating the students to do, gestures to show the emotional state of the characters in the story she told, and paralanguage to imitate the voices of different characters in the story in order to endow them with personality and activeness.

In the case of NT1, the non-verbal communication variable worked against students' English production for she is not very skillful using non-verbal communication clues to make the FL input learnable; instead, she relied on picture-cards to have the students understand data and used Spanish when she did not have visuals to scaffold input. In spite of this, whenever NT1 did support the TL data with appropriate body language, her students understood and expressed their ideas in English.

The other independent variable that could be affecting the results of the correlation stated is children's amount of exposure to and practice of pseudo-communicative data; i.e., aside from making input comprehensible, instructors must design activities in which the students are stimulated to use the vocabulary and structures they will

25 In Joyce Merrill, Culture Bound: Bridging the Cultural Gap in Language Teaching. $5^{\text {th }}$ ed. (Cambridge: Cambridge University Press. 1992) 64-65. 
require for communicative tasks later. "Children employ routinesfixed expressions-as a communication strategy before competence is attained to facilitate interaction," Stephen Krashen explains. ${ }^{26}$ Beginners need to be acquainted with linguistic formulas, trained to make appropriate word substitutions in these patterns to expand the meanings to be transmitted, and encouraged to practice the patterns as much as possible to allow. them some level of TL automaticity for a more confident and successful oral performance.

This was not handled very well by most of the novice-teachers, except in the case of NT4. She designed pre-, while-, and post-teaching and learning activities that helped her students attain a gradual understanding of the topic ("traditional games") that she taught in class. This BEIC student-instructor provided exercises to prepare learners to carry out speech acts related to an advertisement; the children had to create an ad and describe an item from traditional games in order to persuade an intended audience to buy it. Due to accurate preparation for free production, NT4 students were able to prepare the advertisements using vocabulary and formulas they had practiced with the instructor throughout the class and by means of different types of activities.

A third condition derived from the observation reports is that teachers may not be aware of the real amount of Spanish that they use in class. After NT1 had implemented her communicative lesson-plans. the researchers asked all of the BEIC student-teachers how much Spanish they believed they used in the class. The answers varied, but teacher NT1 ${ }^{27}$ said that she kept the use of Spanish in class to the minimum (20\%). However, the data collected shows that NT1 actually used Spanish more (45\%). This percentage could be even higher, we hypothesized, considering that if she used so much Spanish in a class in which she was under «surveillance» and aware that communicative

\footnotetext{
20 Stephen Krashen. Second Language Acquisition and Second Language Learning, $4^{\text {th }}$ ed. (New York: Pergamon. 1985) 8.3.99.

27 Carballo et al.
} 
principles were the core of the researchers' observation task, then, it is probable that NT1 would be exerting less effort in teaching in English when not being monitored and would be tempted to use Spanish more freely and frequently. We do not believe that this noviceteacher or other English teachers increase their use of Spanish in the English class on purpose; rather we suggest that this could be an unconscious process originating from what we have called the «Frustration Phenomenon.»

Initially, when the BEIC student-teachers were confronted with children's lack of comprehension before their English output, they might have felt annoyed, disappointed, and/or dissatisfied about the situation and with the pupils and themselves. Depending on the development of the novice-instructors' teaching skills and strategies and on their particular personality traits, they dealt with the Frustration Phenomenon (FP) in two ways: 1) surrendering easily and rapidly before the effects of the FP, therefore using Spanish to solve their students' constraints in comprehending FL input, or 2) using nonverbal communication skills, visual aids, and others and implementing teaching strategies such as explaining, giving examples, using synonyms, asking questions, etc., until the students were able to gather enough clues to achieve understanding.

In the BEIC major, the student-teachers have been trained to develop and implement different strategies to facilitate comprehension, yet a close examination of the BEIC curriculum reveals that there are no specific courses in which non-verbal communication teaching strategies are included. Scholars such as Eileen McEntee, Larry Samovar, Ned Seelye, Claire Kramsch ${ }^{28}$ and others have acknowledged the relevance of non-verbal communication skills for the teaching/ learning of a second language, for these skills endow speech acts with

\footnotetext{
Eileen McEntee. Comunicación intercultural: bases para la comunicación efectiva en el mundo actual (New York: McGraw-Hill, 1998): Samovar (1998): Ned Seelye. Teaching Culture: Strategies for Intercultural Communication (Lincolnwood. Illinois: National Textbook Company, 1993): Claire Kramsch, Context and Culture in Language Teaching (Oxford: Oxford University Press, 199.3).
} 
the individuals' intentional, cultural, social, and linguistic contexts required to transmit their ideas and then to be decoded easier and more accurately. Apparently, however, the importance of these skills has not been fully recognized in the major.

Based on the evaluation of the novice-instructors' teaching performances in primary schools, their discussions in the BEIC course, and on our interaction with them in formal and informal contexts, we realized that it is urgent to include non-verbal communication content explicitly in the major. Two of the novice-teachers were very skillful in non-verbal communication, but we discovered that it was due to their personality, not their training in the major. The advantage of these BEIC student-teachers is that they are very determined, perseverant, patient and have great potential for research. These personality traits had stimulated them to deal with children's comprehension constraints from a kind of «warrior-like» perspective; they were always searching for the most efficient mechanisms to make input comprehensible and try them out on the class. The other two students were impatient and had not developed research skills as much; they preferred to explain the givens in the class based on their own criteria and would make rapid judgments on the issues without trying other investigation strategies.

Notwithstanding the above, all four BEIC novice-teachers are truly interested in teaching English to children and have a vocation for it. Therefore, we believe that with formal training all of the noviceinstructors can develop high-standards of non-verbal communication skills and be encouraged to adopt the warrior-like attitude that is required to deal with the FP in the most effective way.

Overall, the above discussion and examples show that using English to teach English fosters a desire in children to use the language and leads to success in the task; these, however, are two conditions that are achieved only if instructors make the FL learnable, and oral performance attainable. Teaching English through English is then very pertinent for teaching the FL to children from primary schools. What 
constrains the implementation of this principle is not the school's conditions or the children's cultural patterns, but rather the teachers' lack of ability and/or negative beliefs about the issue. It is not the students' fault - at least not all-, it is the product of an inconsistency in the BEIC curriculum that has omitted relevant contents that these students must approach on behalf of their integral, efficient and consistent professional development.

\section{Acquiring FL Through Experiential Learning}

A core element in the theory of L2 learning stated in communicative approaches is the belief that students build their own knowledge, which is achieved by experiential learning; i.e., "learning by doing (experimenting), and addressing language inductively by discovery to activate strategies that allow students to take charge of their own learning process." ${ }^{29}$ Nevertheless, for this process to be effective, pupils must be exposed to a great variety of "real-world" experiences that must be graded to consider pupils' age, interests, and academic and FL linguistic background.

Experiential learning was usually carried out efficiently by the BEIC students. Their lesson-plans were student-centered, themebased, and communicative. The children were truly excited about the stories, songs, and dialogues on which the classes were based, and most of the time, these students were eager to participate in the different learning activities the teachers proposed. To follow this principle, instructors must take advantage of the students' previous experiences to have them bridge what they already know to the new input and take pride in doing it themselves. Experiential learning is centered around the students and triggered by concrete experiences carefully planned by educators considering factors such as age, interest, and language competence.

29 Brown. 224. 
The BEIC students had a purpose for having the primary school pupils manage English input through their cognitive, affective, and psychomotor domains; however, experiential learning was slowed down by some of the aspects discussed above: the lack of clear instructions to carry out a task, the decontextualization of the FL by using Spanish, and the mismanagement of the intermediate learning stage (while-listening, while-reading, pseudo-communicative, controlled writing). Here we want to emphasize the pertinence of this principle in the primary school contexts observed, and that again the mismanagement of experiential learning is due to the instructors' lack of training in carrying out the while-learning stage more effectively.

In the BEIC, planning is emphasized in several courses, but it seems to be that the weight of efforts is placed on teaching the pre and post learning stages. It might also be that all stages are covered evenly, but that the while stage (practice learning stage) needs more attention. By emphasizing this practice phase, BEIC students can become aware of how significant it is for children to be able to interact with English input in order to produce spontaneous outcomes. As Nunan ${ }^{30}$ explains, "the function of an educational system is to create the conditions whereby learners might generate their own skills and knowledge"; ELCL instructors and curriculum designers of the BEIC should address this issue.

Whatever the reasons were for the BEIC novice-teachers' incomplete competence development to lead children through the while-learning stage, there were questions with no clear answers but the inferences we stated above. For more information, we relied on the questionnaires completed by all the BEIC students, and the eight recorded open interviews with their professors.

31) David Nunan, Second Language Teaching and Learning (Boston. MA: Heinle and Heinle. 1999) 4. 


\section{Data Collected from Surveys and Interviews}

We carried out a survey among all the BEIC students (levels IIV). The objective was to obtain data to determine how many of the BEIC student-teachers believed in the communicative principles that we were testing in this research, at what stage of the major they trusted these principles more and when they began to question the principles' pertinence began. The organization of the questionnaire gradually introduced the topic to obtain information from the students on interaction, partial immersion, and experiential learning. For more reliable answers, we tried to detract from the importance of the issues by using the expression, «Do you believe that it is possible to...?", in some of the items.

We also interviewed eight professors of the BEIC program using an open interview, with direct questions on the issues of study and the interviewees had to provide this data based on the inferences they had made on their formal and informal encounters with the BEIC studentsteachers, and by means of any other sources from which they had been able to obtain information (reaction papers, observation reports, and other types of assignments in which these students had to react to aspects of the teaching/learning process). Each interview took more than 30 minutes, although it was initially expected they would last only 15 minutes, at the most. The professors had much to say about the topics of the questionnaire and we did not limit their intervention, since they were not only providing the information requested but were expanding on how to solve the teaching/learning problems they were describing. The tapes were transcribed to use the printed documents for the analysis.

The surveys applied to all BEIC students confirm that, although they are trained how to teach English using communicative approaches, $35 \%$ of them do not believe that the partial immersion principle can be successfully applied in primary schools in Costa Rica. Some of the arguments that these students use to justify this position are: "Children 
do not comprehend when they are taught only in Iinglish,» «there is not enough time as to allow primary school students 1) understand what is being said in English,» «teaching English only through English is not done in public schools in our country» and «instructions are explained better in Spanish.»

In contrast, $65 \%$ of the student-teachers of the BEIC major say that they believe in partial immersion because "Children get used to English when they are exposed to it all the time," and "By the use of English, students' learning of the FL becomes more integral and therefore meaningful." In spite of this, some of the BEIC professors say that they are not so sure that these students really teach classes using whole English. Professors who have observed some studentteachers' instructing children report that there is more use of Spanish in the class than the students are willing to acknowledge. If we compare the above statements of the BEIC students to the findings from the field observations of the present research, we can see that they coincide with that stated by the professors of the major. For some reason, most of the student-teachers claim to believe in the partial immersion principle, but actually they do not stick strictly to it.

It seems to be that some student-teachers are not aware that there is an array of strategies to make English input comprehensible to the students, for they keep claiming that scolding students and giving instructions is better done in Spanish. Some of the students mentioned non-verbal communication and communication strategies as being means to scaffold comprehension, but other student-teachers ignore these pathways to scaffolding input or do not believe in them.

The surveys also provided information on the tendency of BEIC students to work for private rather than public schools. From 52 students surveyed, 31 report that they are working teaching English to children: $56 \%$ in private institutions, $29.37 \%$ at their home (also private), and $14.57 \%$ in public institutions. From data in the survey, it canbe inferred that this tendency to avoid working in public institutions could point to the concern the students feel for not knowing whether 
they are capable of dealing with discipline in large groups, lack of materials, and time constraints in primary school.

According to some professors of the major, the student-teachers might not be able to cope with the challenge of teaching in public schools because they believe that it is impossible. First, too early in the major they are exposed to observe in-service teachers in public institutions teaching English, but the structural teaching approaches that these student-learners often observe being implemented in the "real English classes" are not congruent with the communicative teaching perspectives which the BEIC major deems appropriate. Second, it might be difficult for the BEIC teacher-students to believe that teaching only in English is possible when many of their professors in the major do not do so, and consequently do not have enough experience to teach them how to solve the problems that arise in a real class with real children when using communicative approaches such as partial immersion.

Another limitation made evident by these two research instruments (surveys and interviews) is that the BEIC student-teachers began to work too soon (at the beginning of the second year of the major). This does not enable them to be linguistically and pedagogically mature to face the experience properly. Not having developed teaching skills sufficiently might be a cause for the student-teachers' frustration when they start working and cannot manage a class using communicative principles. Some professors commented that the fact that the student-teachers began to work so early in their major also reduces their opportunities for learning well, since working full time in a school does not leave these learners enough time to go about their undergraduate studies in depth.

In addition, some BEIC professors state that because of the evening schedule in which the program is offered, the students are more tempted to start working during their first years in the program, because their schedule allows them to. They work in the mornings and afternoons at primary schools and study in the evening. This situation 
also makes it difficult for the student-teachers I I p!. 10 class on time since their job often overlaps with the first hill luwur of most of the courses in the major. Some professors reporl llinl llicy cannot began their classes at 5:00 p.m. as they should since In! is of their students, especially those in III and IV levels, which liave more working students, arrive late (20 to 40 minutes). This comlal be another aspect that is contributing to the students' delay in devc/oping the appropriate teaching skills to implement communicativc l'atching principles appropriately.

Regarding interaction and experiential l'illuing, most learners say that they believe in these principles and impleml'nt them in class. However, the de-contextualization of the English class by using Spanish frequently is a condition that affects llic wher principles as well. If the teacher is speaking Spanish $50 \%$ of llo limc, the interaction of the students with and through the TL is only pirtial. Moreover, it was observed in the classes implemented by the lour BEIC noviceteachers (subjects of this study) that there is a correlation between instructors' use of Spanish for teaching with the strategies that children use to interact in class: the educators' use of 'Spanish triggers the children's use of Spanish. In addition, experiential learning involves approaching the TL through real world experiences, but they are meaningful only if the TL is used as a vehicle. Thus, learning-by-doing experiences should be planned to make English, not Spanish, meaningful to the children.

As seen above, if the BEIC students were better equipped to teach English implementing communicative principles in the primary school, they would be much more successful in this endeavor, but because of the inconsistencies of the BEIC major, the student-teachers may not achieve the linguistic and pedagogical skills to accept the challenge of teaching English to children in "real-world" educational settings. 


\section{Findings}

The analysis of the data collected in this first phase of the research confirmed that communicative principles have internal validity; i.e., they are effective per se and are also very pertinent to teach English to Costa Rican children. This was concluded because whenever the BEIC student-teachers used these communicative principles appropriately, they accomplished the purpose of stimulating primary school learners' comprehension and production in the FL. Scholars acknowledge that to facilitate students' TL proficiency success through communicative principles, instructors need to identify and analyze the aspects that-given conditions of the educational setting and students' and teachers' as well-facilitate or constrain the teaching and learning processes. Todeal with the weaknesses of these processes, Kathleen Graves ${ }^{31}$ advises teachers to "problematize"; i.e., "...teachers need to identify the [teaching/learning] challenge(s), analyze all options, determine which individuals could help, and make a plan (strategies) to carry it out." In the case of the "Value of Curricular Introspection" research, it was observed that the size of a group, the lack of equipment to teach English, time constraints and pupils' cultural background did pose a challenge for the BEIC studentteachers to implement communicative principles, yet whenever appropriate teaching strategies were used to deal with these external variables, the communicative principles applied activated children's cognition and stimulated their language skill development. Consequently, external variables were discarded as the origin of the disparate phenomenon generated among the students and the BEIC professors and curriculum designers with regard to the pertinence of communicative principles.

On the contrary, we discovered that internal variables were at the core of the research problem. The initial sample group under study

31 Richards (ed.), 33-35. 
(four BEIC student-teachers) had important non-verbal communication and pedagogical skill deficiencies. The analysis of data garnered found a correlation between the above educational constraints and some particular conditions of the BEIC program such as its fragmented curriculum; scanty integration or complete absence of relevant course contents that contextualize learning, some BEIC professors' lack of theoretical knowledge on teaching English to children and/or their scanty previous experience teaching English in primary schools, and finally, a deficient coordination of the BEIC endeavours on the part of both schools (ELCL and CIDE) sharing the management of the curriculum.

Due to these curricular inconsistencies, some BEIC students did not use non-verbal communication skills appropriately while teaching. This becomes a limitation, as Birdwhistell has pointed out that "...only $35 \%$ of the social message is transmitted through words; the remaining $65 \%$ is communicated by non-verbal communication." Although this shows how relevant non-verbal communication skills can be to teach the TL, they are not emphasized during the major. ${ }^{32}$

It was observed that due to this incomplete development of nonverbal communication skills, the student-teachers experienced what we have called the "frustration phenomenon": an emotional state including desperation, annoyance and intolerance for not having access to the appropriate mechanisms to rely on to facilitate children's comprehension of the FL; in order to be relieved from this hardship, the student-teachers tended to switch to the pupils' mother tongue the very first (or second) time that the children complained about not being able to understand English input. Unfortunately, coming back to English becomes very difficult thereafter, since neither teachers nor pupils want to abandon the emotional and cognitive comfort that using ones' native language provides. In contrast, BEIC students with more

32 In McEntee. 383-384. 
developed non-verbal communication skills resisted for a longer period of time the temptation to render to the frustration phenomenon.

The other constraint observed was that although the studentteachers did well with the teaching of pre and post language skill development stages (pre-listening, post-listening), they did not carry out effectively the while-learning stage; i.e., the "practice" stage for reading, listening, speaking, and writing. At the beginning of the class, the students were able to engage the children in the activities to have them interact with the FL, but practice was somewhat neglected, so very of ten the pupils were not ready to express themselves in English during the class or at the end.

\section{Recommendations}

Having studied the BEIC curriculum, we can advise curriculum designers to integrate pedagogical contents in carefully-sequenced courses. They could design one course including contents orienting planning for listening comprehension and oral production along with materials design to support comprehension, and assessment and evaluation to measure students' progress in developing these skills. Then, a second course could incorporate contents guiding planning for reading comprehension and written production along with materials design to support comprehension, and assessment and evaluation to measure learners' progress in developing these other skills. The two courses would allow students to see the interrelation of the different pedagogical components more clearly. In turn, merging the contents would also free space to design other courses required to support students' development of non-verbal communication skills.

It is also essential to include courses on classroom management, on BEIC and MEP curriculum contents, and on a historical overview of the changes that the Costa Rican primary school English curriculum has undergone. This would enable BEIC students to get a retrospective view of the teaching pathways that the ELCL has experimented with, 
the theorization derived from those methodological experiences, and the products that have been generated as a result of those practices. This knowledge can become the point of departure for BEIC studentteachers to engage in their own exploration on teaching methodologies, develop trust in BEIC professors and curriculum designers, be motivated to assure the pioneering role required for teaching English to children through approaches that work and give them pride to be studying in the ELCL.

In the courses emphasizing lesson-planning content, the «problematizing» component should be added. It implies reflecting on the probable teaching/learning problems that could arise in class because of different circumstances and previewing ways to solve them. It was observed that none of the BEIC students, who were subjects of this research, knew how to deal with certain negative situations in the class. These problems could have been solved before teaching the class if the student-teachers had thought of the strategies to approach the problems a priori while planning.

It is also very important for the student-teachers to implement the lessons they design (as part of their course projects) in a real educational setting. They must be observed and evaluated by an ELCL professor, who can give them valuable feedback, and not by an inservice English teacher who might not have knowledge about the principles of the communicative approach or any experience teaching with them. These students could video-tape some of their lessons to get feedback from BEIC professors and classmates on the teaching/ learning strengths and weaknesses observed. This would enable the whole group to benefit by experience of solving the problems that arise in a real class. This could be a course project and a source for a portfolio as well.

Another recommendation is that the ELCL could create a bank of in-service teachers with experience in communicative approaches, and motivate them to allow BEIC student-teachers to observe their lessons. If this first observation experience validates what the students 
are learning, they would modify their view of the communicative approaches taught in the BEIC. Once the students graduate, they could also belong to this group of communicative in-service instructors.

Finally, the BEIC curriculum designers must find a way to provide students with more opportunities to develop the FL. Teaching the CIDE pedagogy courses in English instead of in Spanish would contribute to this. The student-teachers' command of English can also be improved by promoting the use of English for formal and informal interaction among students and professors in and outside the classroom. Both strategies would provide more practice and exposure to the TL.

In spite of this research, we are still not satisfied with the results because many unanswered questions remain; for that reason, a second phase is now in progress. However, this first phase has already provided us (as teacher trainers of the PROCAPRI outreach program and BEIC professors) with a starting point for implementing the above recommendations. In addition, these results have been shared with professors, students, and authorities of both departments in charge of the major, and as a result, this study is supporting the BEIC redesign committee in its endeavours to improve the major's curriculum. Likewise, PROCAPRI teacher-trainers have already started to work on reinforcing the ELCL professors' theoretical and practical grounding on communicative methodologies for teaching English to children. At the beginning of 2008, they implemented three 4-hour workshops; the training provided by PROCAPRI will enable these professionals to perform even more efficiently in the BEIC. CIDE authorities have also learned from this research about the need to teach pedagogical courses in English and they have already agreed to hire professors with a good command of English.

In consonance with the above, this ongoing research has already had, and it is hoped will continue to have, a significant impact on three instances: The first is the redesign of the BEIC curriculum to make it more integrated. Secondly, this will enable student-teachers to become more efficient English instructors in primary schools. Third, it is 
hoped that it will thereby enhance the opportunities of many Costa Rican children to achieve a better bilingual foundation. Thus, the research has had a positive impact in the linguistic arena since it is an example of how an apparently isolated teaching/learning phenomenon such as the disparity of criteria among BEIC actors on the pertinence of three communicative teaching principles was actually a sign of many other educational problems. 